\title{
Long-COVID: Um Desafio para a Comunidade Médica e para o Serviço Nacional de Saúde
}

\section{Long-COVID: A Challenge for the Medical Community and the National Health Service}

Sandra BRAZ $\square^{1}$

Acta Med Port 2021 Sep;34(9):567-568 - https://doi.org/10.20344/amp.16991

Palavras-chave: COVID-19/complicações; Portugal

Keywords: COVID-19/complications; Portugal

Decorridos mais de 18 meses desde o diagnóstico do primeiro caso de COVID-19, esta continua a ser uma doença nova que desafia a comunidade científica a aprender em tempo real. Os relatos dos doentes recuperados, referindo sintomas e sinais que persistem semanas a meses após a resolução da infecção aguda, obrigam-nos a reflectir sobre a história natural da infecção por SARS-CoV-2. Embora não exista ainda uma definição consensual, a long-COVID é uma condição caracterizada por manifestações clínicas multissistémicas, do foro respiratório, cardiovascular, neurológico, gastrointestinal, renal e/ou músculo-esquelético, que surgem habitualmente na fase aguda da infecção ou imediatamente depois, não são explicáveis por um diagnóstico alternativo e persistem além das quatro semanas de doença. ${ }^{1}$

Os sintomas podem manifestar-se isoladamente ou em associações diversas, surgir vários meses após a doença aguda e ter uma evolução cíclica com períodos de remissão e de recidiva.

A utilização de nomenclaturas diferentes para designar esta entidade e a ausência de critérios universais definidores do diagnóstico têm comprometido a identificação de casos clínicos, a investigação da doença, nomeadamente a sua fisiopatologia, e a partilha de informação.

Não existem dados da prevalência da long-COVID em Portugal. Os números referentes a outros países são díspares e reflectem a ausência de uma uniformização de terminologia e de critérios de diagnóstico. No dia 31 Julho de 2021, tinham sido diagnosticados em Portugal cerca de 968 000 casos de infecção por SARS-CoV-2. ${ }^{2}$ Se assumirmos que $10 \%$ a $30 \%$ destes doentes desenvolvem sintomas persistentes, como é referido por alguns autores, facilmente reconhecemos a sobrecarga adicional que esta doença representará para o Serviço Nacional de Saúde (SNS) e para a economia do país. ${ }^{3}$ Serão mais de 96000 doentes, a maioria numa faixa etária profissionalmente activa, a necessitarem de cuidados médicos a médio-longo prazo e que não conseguem retomar a actividade profissional, nos primeiros meses após a infecção, devido ao compromisso funcional causado pela doença.
Foram os doentes recuperados, mas com sintomas que comprometiam a sua qualidade de vida e desempenho profissional, que, sentindo-se incompreendidos e insatisfeitos com as soluções apontadas pelos profissionais de saúde, deram o alerta para esta doença nova e reclamaram o seu reconhecimento. Recusaram o rótulo de "dano psicológico", organizaram-se em associações e grupos de apoio e divulgaram online o conceito de long-COVID. Foram, e ainda são, usadas outras designações, como síndrome pós-COVID-19 e COVID-19 crónica, mas long-COVID parece ser a mais consensual por ter implícito o continuum de sintomas da fase aguda, sem o corte abrupto sugerido pela "síndrome pós-COVID" e o peso da cronicidade de outros termos. Mais recentemente o termo long-COVID foi reconhecido pela comunidade científica, surgiu em revistas científicas com revisão por pares e tem sido tema de editoriais e artigos de revisão e de opinião em diversas revistas científicas. ${ }^{1,3,4}$

Alguns autores referem-se à long-COVID como uma síndrome pós-infecciosa idêntica à encefalomielite miálgica $(E M)$, síndrome de fadiga crónica, associada ao SARS-CoV-1, ao vírus Epstein-Barr e à Coxiella burnetti, e à síndrome pós-doença de Lyme. A EM é uma doença crónica multissistémica caracterizada por um conjunto de sintomas, fadiga, distúrbios do sono, alterações neurocognitivas, intolerância ortostática e mal-estar pós-esforço, agravados pelo stress e esforço físico. Não há actualmente evidência científica que o SARS-CoV-2 constitua um trigger para a EM. Apesar dos mecanismos etiopatogénicos da long-COVID não terem sido ainda esclarecidos, são apontadas várias hipóteses, nomeadamente a persistência do SARS-CoV-2 nos tecidos, a disfunção imunitária e a resposta inflamatória desencadeadas pelo vírus e fenómenos disautonómicos. A presença do vírus na mucosa gastrointestinal foi documentada histologicamente em um terço de doentes submetidos a biópsias quatro meses depois da infecção aguda. ${ }^{4}$ Contudo, a presença do vírus nos tecidos não é nem condição necessária, nem sinónimo de persistência da doença. Daniel Altmann et al, num artigo de opinião publicado na $B M J$, refere que os mecanismos

\footnotetext{
1. Serviço de Medicina 2. Hospital de Santa Maria. Centro Hospitalar Universitário Lisboa Norte. Lisboa. Portugal.

$\square$ Autor correspondente: Sandra Braz. sandrabbraz@gmail.com

Recebido: 10 de Agosto de 2021 - Aceite: 10 de Agosto de 2021 - Online issue published: 01 de setembro de 2021
} Copyright @ Ordem dos Médicos 2021 
fisiopatológicos subjacentes às doenças auto-imunes podem constituir um modelo conceptual relevante para o padrão de sintomas da long-COVID. ${ }^{4}$ Faz alusão ao lúpus, enquanto doença de um sistema único, o sistema imunitário, mas com afecção de vários outros e manifestações multissistémicas, e à evolução clínica da esclerose múltipla, com padrão de remissão-recaída idêntico ao de alguns casos de long-COVID. Refere-se ainda às manifestações de auto-imunidade e resposta inflamatória persistente associadas a outras infecções virais, como são os casos do Ébola, o Chikungunya ou o Epstein-Barr. As semelhanças da long-COVID com outras patologias, infecciosas ou auto-imunes, são inegáveis, mas na fase inicial de uma doença nova, estabelecer analogias com outras doenças pode ser redutor e comprometer a investigação de um modelo fisiopatológico com características singulares. O conhecimento da fisiopatologia da long-COVID é crucial para o desenvolvimento de intervenções terapêuticas, que podem vir a modificar a trajectória da doença e mitigar o seu impacto. A persistência do vírus nos tecidos reforça a importância da investigação de fármacos anti-víricos e a disfunção imunitária associada ao SARS-CoV-2, além das implicações terapêuticas, alerta-nos para o risco futuro de patologias auto-imunes nos doentes que tiveram COVID-19.

Os estudos observacionais de follow-up de doentes com long-COVID, divulgados em revistas científicas com revisão por pares, oferecem-nos uma caracterização detalhada das manifestações clínicas e uma perspectiva da sua prevalência e evolução temporal. ${ }^{1}$ Verificamos que os doentes diferem entre si, no que diz respeito ao padrão de sintomas e à gravidade clínica, e que a maioria se mantem sintomática 6 meses após a infecção aguda. Contudo, não sabemos quais e quantos doentes irão recuperar e os que vão apresentar sintomas incapacitantes no futuro. Quanto aos factores de risco de evolução para long-COVID, não foi demonstrada uma correlação directa entre a gravidade clínica da doença aguda e o risco de long-COVID e o pressuposto que os doentes com doença crítica têm uma maior probabilidade de desenvolver sintomas persistentes está errado. A idade, o sexo masculino e a obesidade, factores de risco para COVID-19 grave, não estão associados a risco aumentado de long-COVID. Deve ser investigado o potencial de risco de outros factores, demográficos e clínicos, e o impacto dos tratamentos instituídos na infecção aguda não deve ser descurado.

A long-COVID constitui um desafio para a comunidade médica. A novidade da doença e a ausência de recomendações de organizações e sociedades científicas, que guiem a marcha diagnóstica e tratamento, gera ansiedade e insegurança. Além da fisiopatologia, desconhecemos a epidemiologia, o curso natural da doença e as potenciais sequelas. Estamos, em muitos aspectos, perante o desconhecido, mas a gravidade e dimensão do problema exige uma resposta sólida e estruturada. Os médicos que acompanham estes doentes têm de investir na colheita, registo e organização de dados, promover a criação de plataformas nacionais de registo e organizar-se em grupos de trabalho que facilitem a troca de informações. Mas, citando Daniel Altmann, é necessário ir além dos estudos observacionais e promover estudos de intervenção. A inclusão de doentes com long-COVID em ensaios clínicos é já uma prioridade reconhecida por alguns países e centros de investigação. Destaco o trabalho da Organização Mundial de Saúde (OMS) e o programa SARS-CoV-2 Recovery Cohort, uma iniciativa do National Institutes of Health, que inclui estudos prospectivos de coorte que pretendem avaliar os efeitos da infecção a longo prazo e acompanhar a trajectória de sintomas ao longo do tempo. ${ }^{5}$

Steven Philips et al, num artigo recentemente publicado na NEJM, refere-se à long-COVID como o próximo desastre nacional de saúde. ${ }^{3}$ Como podemos evitar que uma condição quase desconhecida, que afecta um número tão significativo de doentes, abale um SNS já com tantas fragilidades? Através de uma resposta coordenada da política nacional de saúde, investindo na prevenção da infecção e na investigação da doença, definindo planos de intervenção adaptados à realidade do país e ajustáveis à evolução da pandemia e, acima de tudo, gerindo, de forma realista e responsável, os recursos humanos e as instituições.

A long-COVID tem características singulares. $O$ alerta para os sintomas persistentes foi dado pelos doentes, os mesmos que reclamaram o seu reconhecimento como "doença nova", que a mediatizaram e alertaram para o impacto que poderia ter na saúde, na economia e na sociedade. A comunidade médica mostrou-se ambivalente e reconheceu, ao olhar para o passado, a possibilidade de estar perante uma nova síndrome pós-viral, mas não afastou, de imediato, o contributo de uma componente psicológica. A abordagem desta doença é também um exercício de humildade. Não há sinais ou sintomas patognomónicos, não há biomarcadores da doença nem testes diagnósticos que a afirmem ou excluam. O que podemos fazer? Tão simples quanto assumir que não sabemos, identificar o que precisamos saber e melhorar e criar as condições para que isso aconteça.

\section{CONFLITOS DE INTERESSE}

A autora declara não ter conflitos de interesse relacionados com o presente trabalho.

\section{REFERÊNCIAS}

1. Crook H, Raza S, Nowell J, Young M, Edison P. Long covid mechanisms, risk factors, and management. BMJ. 2021;374:n1648.

2. Portugal. Worldmeter. [acedido 2021 Jul 31]. Disponível em; https:// www.worldometers.info/coronavirus/country/portugal/

3. Philips S, Williams M. Confronting our next national health disaster Long-Haul Covid. N Engl J Med. 2021. DOI: 10.1056/NEJMp2109285.

4. Altmann D, Boyton R. Decoding the unknowns in long covid. BMJ. 2021;372:n132.

5. National Institutes of Health. [acedido 2021 Jul 31]. Disponível em: covid19.nih.gov/sites/default/files/2021-02/PASC-ROA-OTA-RecoveryCohort Studies.pdf. 